\title{
Intermediary objects in the workspace design process: means of experience transfer in the offshore sector
}

\author{
Carolina Conceição ${ }^{\mathrm{a},{ }^{*}}$, Gislaine Silva ${ }^{\mathrm{a}}$, Ole Broberg ${ }^{\mathrm{b}}$ and Francisco Duarte ${ }^{\mathrm{a}}$ \\ a Programa de Engenharia de Produção, COPPE, Universidade Federal do Rio de Janeiro, Centro de Tecnologia, \\ bloco G, sala G209, Ilha do Fundão, Caixa Postal 68507, Rio de Janeiro, Brazil \\ ${ }^{\mathrm{b}}$ DTU Management Engineering, Technical University of Denmark, building 424, DK-2800, Lyngby, Denmark
}

\begin{abstract}
The aim of this paper is to discuss the use of intermediary objects in the workspace design process of offshore accommodations module. The integration of ergonomics in the design process can lead to better work conditions, more effectiveness in the work process and less health and safety issues. Moreover, it is more efficient in terms of cost if ergonomics is considered from the initial phases of the project, as the potential costs of the redesign, the possible losses and the down-time in the operation of the platform would be more increased. The goal, then, is to discuss the integration of ergonomics and users involvement in the design process of accommodations modules, focusing on the transfer of information from reference situations by the use of intermediary objects during the process. In this paper we will present two tools developed to be used as intermediary object(s) aiming at transferring the experience from the use to the design in the specific field of offshore accommodations module.
\end{abstract}

Keywords: ergonomic work analysis, ergonomic recommendations, accommodations module

\section{Introduction}

Aiming at introducing work logics in the workspace design process, ergonomics has been present in offshore platforms design, although sometimes only at the end of the process when there are already some irreversible conditions. Intervening in the basic design by integrating ergonomic principles derived from the analysis of existing situations aims to incorporate the work dimension from the start of the design process.

Although the range of technologies for developing deepwater exploration and production platform projects is increasing, operational experience transfer between projects is still modest. In other words, there is a lack of feedback from projects using information derived from the use of operating platforms. The ergonomics integration in offshore projects aims to support the responsible for the design in decision making from a realistic anticipation of what will be the work of future users.

The central question for ergonomics in projects should be the prediction of use. According to Falzon [12], what is being done to address this issue goes through three approaches: the ergonomic work analysis, the adaptive systems and the developmental approach. This research, however, is different and, at the same time, complements these approaches. The intention is to contribute through the observed use in reference situations with design projects before they even start, that is, from its basic studies.

Gherardi \&Nicolini [13] point the notion of 'intermediaries' as central to the circulation of knowledge among actors in a design process. These intermediaries would work both as a form of representation of a specific knowledge (in the present case, the ergonomic knowledge) and of its translation (to the designers). They suggest four types of intermediaries, one of them being 'texts and inscriptions'. Vinck [19],

\footnotetext{
* Corresponding author. E-mail: carolina@pep.ufrj.br.
} 
on his turn, highlights the time spent to design, negotiate and circulate different kinds of objects, such as texts, instruments, among others.

Regarding this notion of intermediaries and the situation described above about ergonomics and design projects, the aim of this paper is to present two developed tools and discuss their use as intermediary objects in offshore design processes. This work is part of the studies for the main author's D.Sc. Thesis.

\section{Methods}

A research project was carried out by the UFRJ Production Engineering Program and a Brazilian oil exploration and production company's research centre from 2007 to 2009 . The objective was to generate ergonomic guidelines both for the accommodations and process areas of offshore platforms, rescuing use experience and transferring it to future oil platform design projects. In this paper, however, focus is given to the accommodations module environments.

In a first stage, interviews were carried out with workers of the different environments in a FPSO (Floating, Production, Storage and Offloading) Unit used as the main reference situation during the research project. Eight three-day boardings were made in this unit. Also, in some of the environments, follow-ups of activities developed by the workers occurred. Pictures were taken and video recordings were made during these follow-ups. The methodology used was the ergonomic work analysis [14].

The activity that will be developed in the space to be designed and built, being a form of conduct in response to the set of tasks that the worker must develop, does not exist yet. Through the "paradox of ergonomic design" one comes to the notion of the "possible future activity", where it is not possible to analyze the future activity, but try to predict some of its characteristics through the analysis of existing similar situations [7]. It is then possible from the analysis and understanding of existing situations, to make use of this information in design projects.

This way, in a second stage, the gathered information about the activities carried out on board, as well as some initial recommendations, were validated with workers of other units and with designers. In a third stage the recommendations booklet was developed, as means of transfer the operational experience to the designers in new units design processes. The booklet had a final validation with two experienced designers.
After the research project, a second tool was developed by the first author to be used together with the recommendations booklet (a zoning pattern). This was made in order to reinforce the experience transfer in a practical way to be used by the designers. The zoning pattern was discussed with a group of designers in two workshops carried out in 2011.

\section{Ergonomics and design projects}

Projects have traditionally been characterized by an organization virtually isolated from the operating environment [24], resulting from the company's specifications, legal requirements and qualified designers. According to Pagenhart et al. [16], however, there was a need for a change in the design process and transfer of relevant experience of operating environments, beyond the traditional elements of design, has become crucial to achieve a proper design "first hand". Once operational experience is clearly missing to the majority of designers, the experience transfer is the main source of practical information for the development of design projects [16].

\subsection{The role of intermediary objects}

As stated by Broberg [3], many engineers are not acquainted with ergonomics, being a major strategy to supply them with ergonomics information, principles and data. "By transferring ergonomics knowledge and skills to engineers, in a manner in which they can be used, ergonomics can be integrated into engineering." [3] Thus, work simulation techniques through intermediary objects such as floor plans, models, among others, contribute to the mentioned double construction and to the development of design solutions based on ergonomic principles.

Ewenstein \& Whyte [11] point the need to clarify the diverse dimensions of objects to understand their use. "In the literatures, objects vary in the degree to which they are concrete or abstract; stable or in flux; and associated with knowledge work within or across contexts and practices." [11] Intermediary objects, as defined by Vinck et al. [20], "are supposed to be objects that can be communicated and exchanged between design partners. Their goal is to improve exchanges, enable viewpoints from various trades to be expressed and compromises to be achieved". Boujut $\&$ Blanco [1] highlight three main features of intermediary objects: mediation, transformation or translation, representation. And they point that intermedi- 
ary objects are also intermediate states of the product if we consider the objects as mediators translating and representing the future product.

In this sense, as stated by Ewenstein \& Whyte [11], visual representations are certainly a significant, if not the major, way in which the abstract idea of the project is linked with the concrete, in the case of workspace design, the environment itself. This is because "visual representations may embody a wide range of knowledge (...) and can be read in a way that allows professionals with different perspectives to make sense of and contribute to the new product [or environment] development process" [11].

\subsection{The existing ergonomic guidelines and standards}

Ergonomics have traditionally not been considered in engineering design projects. More recently, ergonomics started to be considered, but still in later stages of the project. "Reference books (...) and the development of ergonomics standards have tried to amend this situation by providing ergonomics requirements." [22] However, as highlighted by the authors, the users of these standards normally are non-experts in the field of ergonomics. This way, even with those references, "designers would need to have a good understanding of what ergonomics is and the cost/benefits of using ergonomics information in designs" [18], which can impact on the time allowed to apply ergonomics in the projects as there is a lack of time in early phases.

Design guidelines can be considered as an intermediary interface between the designer and the knowledge about the use. "Therefore, understanding the designer's behavior is necessary to design the guidelines as the intermediary interface (...)." [15] Many times, as stated by Skepper et al. [18], documents are lengthy and time consuming. So, it is paramount that the information given to designers is concise and without extensive references to theory or original research [5].

The existing manuals are not or are very little used in offshore projects, as highlighted by Pagenhart et al. [16]. In fact, even in other projects, "ergonomics standards very often are ignored by design engineers, one of the reasons being that they are formulated in vague and general terms" [3]. Moreover, despite the large amount of information presented in these manuals and standards, many relevant data to the designers are not part of these guidelines [4]. Many are written assuming, implicitly or explicitly, that the designers will read them and discover for themselves how to design the spaces according to the capabilities and limitations of the users [6]. According to Chapanis [6], the misconception is that engineers and designers do not read these handbooks and, when reading, they do not understand the guidelines and do not know how to design to meet them. And indeed, there would be no reason for that to happen, since that the ergonomists are the ones who were 'trained' to do so, not the engineers.

\subsection{The moment to use the intermediary objects during the design process}

In the study reported by Skepper et al. [18], it is already accepted by design actors that the ergonomic guidelines would be more efficient in terms of cost if included in the initial stages of the design process, being the potential cost of the redesign, the damage that can be caused and the downtime in the operation of the platform much higher. However, to ensure their proper use, it is necessary to designers a good understanding of ergonomics and of the cost/benefit of applying the ergonomic guidelines in the design.

Regarding the accommodations module, ergonomics should be included, together with the other disciplines involved, when the arrangements for the module design start to be made. Skepper et al. [18] summarize some literature suggestions for the incorporation of ergonomics information into the various stages of the design processes. According to their description, the conceptual design stage would be the equivalent of the 'beginning of the project'. And in this stage the suggestions are: 1) "reinforcement of ergonomic information in each of the alternative functional areas considered"; 2) "review of the literature to assist with identification of potential solutions"; and 3) "consideration of human interface design by assimilating the user data collected". In addition, the results of the study carried out by Wulff et al. [21] indicates that 'spending time' in the beginning of the process can save time and effort later on.

\section{The intermediary objects developed}

The recommendations booklet was one of the results from the research project. It was developed through the project, based on the ergonomic work analysis and especially in following up the activities on operating platforms. And based on a review of the analysis carried out and on the recommendations booklet, it was developed the zoning pattern. It was 
meant to be a visual representation 'mapping' of the inter-relations among the environments.

\subsection{The development process}

During the research project, the content of the booklet created on the basis of this project was gradually developed in a participative manner. The initial drafts of the recommendations were not intended to be definitive documents, in neither their form nor content. The aim was to make the material available as it was prepared in order to serve as the basis for analyses, discussions, suggestions and validations. The identification of characteristic action situations during the analysis of reference situations permits to raise relevant questions that should be considered since the beginning of the projects. So, based on this information about the activities developed on board and on the analysis of existing standards and guidelines, a set of first guidelines was written.

The recommendations were first validated with the research group and with four designers, in order to align their format to their intended use and intended users. Some reviews and adjustments on the format and the way information was presented followed. A discussion was conducted about the format of the guidelines, regarding mainly which kind of information should/could be extracted from the ergonomic analysis to be transferred to the designers. In this way settings of usage $[9,10]$ were developed as part of the guidelines format in order to describe/generalize the activities that take place in each environment. The goal was to make specific relations between the characteristic situations with the areas each activity took place, highlighting the aspects of the design of the workspaces directly related with those activities. Afterwards, the discussion was about the full booklet structure and each section it would have and how the information would be presented.

During the development of the recommendations, the need of better criteria to define the positioning of the environments within the module was evidenced. This way, after the research project, the zoning pattern was developed in order to fulfill this demand. Based on the recommendations booklet, a section drawing of a generic accommodations module was made to represent the main positioning and inter relations among the environments. Due to important differences that might exist between fix and semisubmersible platforms to FPSOs, a choice was made to focus on the FPSO type, the same as the main reference situation studied. The goal was to test whether a visual tool would help the designers, so the same methodology can be used to develop similar tools for other kinds of platforms.

\subsection{The recommendations booklet}

The recommendations were written in a way not to impose permanent restrictions on future ergonomists who, together with the design team, will execute the detailed design of the new installation. The booklet was subdivided in chapters: the first one regarding general characteristics and recommendations that apply for all environments and the others for each environment separately. Each chapter begins with a general overview of the environment. It is presented the purpose of the place, the main activities held, who works there, and its general location in other platforms. After the general overview, the first section is the 'settings of usage', where are presented the typical use situations of the environment and that should be considered during the design.

The settings of usage have their basis on the characteristic action situations. They were written in order to extract the information focused always on the use of the space and furniture/equipment needed. The notion of settings of usage permits to understand better how the recommendations were constructed and, also, how they should be used. As stated by Duarte et al. [9], settings of usage are "schemes of usage that preserve the essential relations of actual situations, formulated at a higher level of abstraction that are able to advise the activities of designers and ergonomists since early stage in the design of future petroleum platforms".

In the second section, 'conditioning factors and design variables', the main aspects that have to be considered in the design are presented. These aspects may vary from one project to another, that's why it is not possible to assume some characteristics within the recommendations. The third section, 'reference norms and standards', presents the main documents that should be consulted by designers.

The fourth section presents the recommendations, which are presented in hierarchical order, from the most general to the most specific. First, recommendations regarding the layout of each environment are presented divided into three sub-items: 1) positioning, access and flows; 2) dimensioning and layout; and 3) furniture, equipment, dispositive and installations. In sequence, recommendations regarding the environment are presented also divided into three sub-items: 1) thermal comfort; 2) lighting; and 3) acoustics. 
The form and content of the recommendations obey some principles, attempting to satisfy the activity of the designers. However, they do not intend to substitute the participation of an ergonomist during the process. On the contrary, the information given in the booklet permits shorten the time of recognition of the field and guide the situations that should be analyzed. Traditional guidelines do not always attempt to explain the reason for a suggestion, as if its motive were self-evident. Therefore an attempt was made to draw up the recommendations in such a way that in addition to the proposed technical content, the aim/purpose or problem to be resolved was clear. Besides, whenever possible, drawings, pictures and schemes are presented to ease the understanding. This way the guidelines attempted to comprise what should be done, its reasons and, to a certain extent, how this should be done.

\subsection{The zoning pattern}

The importance of thinking about the accommodations module as a whole instead of only each environment separately, regarding the different relations among them, lead to the development of a visual representation of the positioning of the offshore accommodations module's environments. From the use of spaces and the inter-relations identified among them, it was possible to establish a standard relative positioning among the environments. This zoning is a definition of the grouping of sectors in each of the decks, allowing to define their relative positioning.

The format defined for the zoning pattern includes an inter-relations table and a section drawing. The table (Figure 1) was created first, entirely based on the positioning, access and flows recommendations. For each sector the recommendations were summarized in order to make a list of environments with which there should be proximity or distance. This list was then divided into environments within the sector (left side of the table) and other environments (right side of the table).

Next, having this table as the starting point, the second stage was to define how to represent these relations graphically. A zoning is usually represented with plans, but in this case it was not considered the best option, the main reasons being: the difficulty in representing the relations among environments positioned in different decks and, most important, the false image of a 'standard module' plans could lead to. The solution found was to represent the zoning in a schematic section drawing (Figure 2), identifying only the main deck, the production deck and the last deck of the module, considering the case of the more frequent positioning of the helideck above the module of FPSOs.

As in the case of inter-relations table, the different sectors were represented in colored rectangles (each color related to one sector) for easy viewing and identification. The environments were then placed in the schematic section respecting the positioning, access and flows' recommendations. The arrows represent the inter-relations among the environments that are highlighted in the table. Wider arrows when the proximity between environments is fundamental to its functioning, thin arrows when there is an interrelation and the proximity is desirable, and dashed arrows when proximity can facilitate certain activities, but is of minor importance for their development.

Thus, the zoning pattern is intended to complement the recommendations booklet. It brings the first information that would need to be sought during the first studies and arrangements for the accommodations module during its design. Although there is not the addition of new information regarding the recommendations, this tool aims to condense the information about the positioning of the sectors in order to simplify the work of the designers. 
Operation environment + equipment environment

Field operatos's shelter at the process area

Environments in the same level Close to: barbecue area

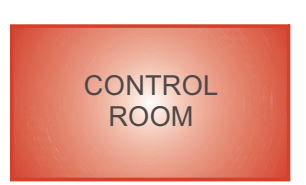

FOOD

SECTOR
Fast access and without obstacles to the process area Close to: coffee shop

Close to: restrooms

Close to: support offices

Close to: meeting and video conference room(s)

Close to: technical library

In the same level and close to: ranch receiving area

Close to: exclusive restroom for food sector workers

Close to: restrooms

Water gallons deposit close to ranch receiving area

Fig. 1 - The developed zoning pattern: part of the inter-relations table

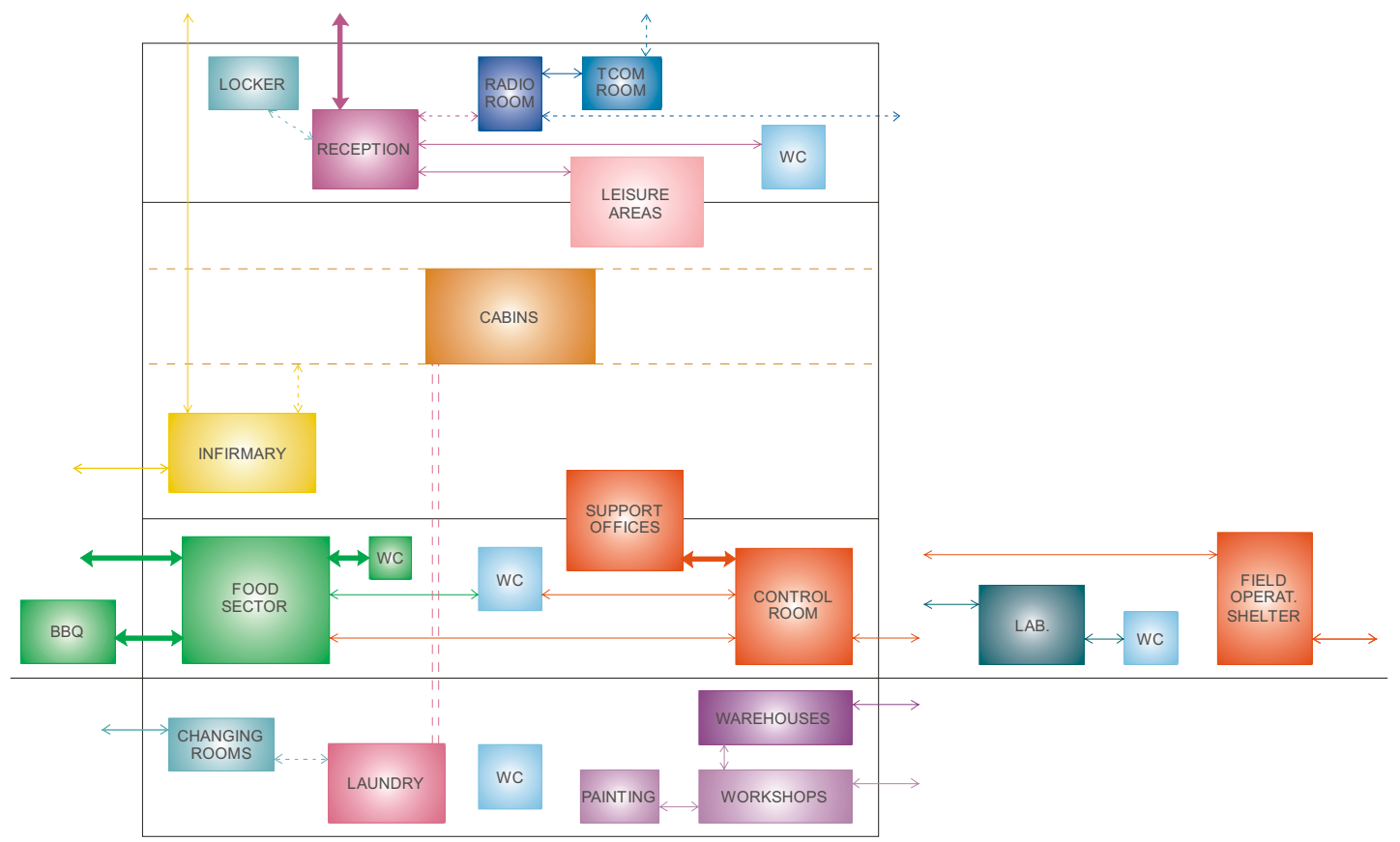

Fig. 2 - The developed zoning pattern: section drawing

\section{The testing of the intermediary objects with the workshops}

The main purpose of the workshops was the validation of the zoning pattern, also developed after the research project was over and therefore not presented to the designers before the workshops. Other objectives were a revalidation of the booklet of recommendations as an intermediate object in the design process and a better understanding of the design process itself within the company.

Two workshops, here called A and B, were held. Both were audio recorded for later analysis. The first author was the mediator in both workshops, presenting, questioning and discussing the proposals that were being made. Workshop A was held with a total of five designers, all architects, working on a thirdparty company that provides design services for the oil company. Workshop B was conducted with two designers, also architects, working outsourced to another company, which has the same kind of thirdparty relationship with the oil company.

\subsection{The structure of the workshops}

For the realization of the workshops a structure with the activities to be performed, as well as issues to be addressed and questions to be asked, was elabo- 
rated. This structure can be divided, broadly, into four distinct stages: 1) presentation of tools and the intended objectives with the workshops; 2) design game; 3) simulation with the recent project of a FPSO; and 4) questions about the design process and use of the tools presented. The proposed design game was based on the work done by Broberg [2] and Seim $\&$ Broberg [17]. In the present work it consisted of a proposed activity to the designers so that they would develop their own zoning pattern (Figure 3 ).

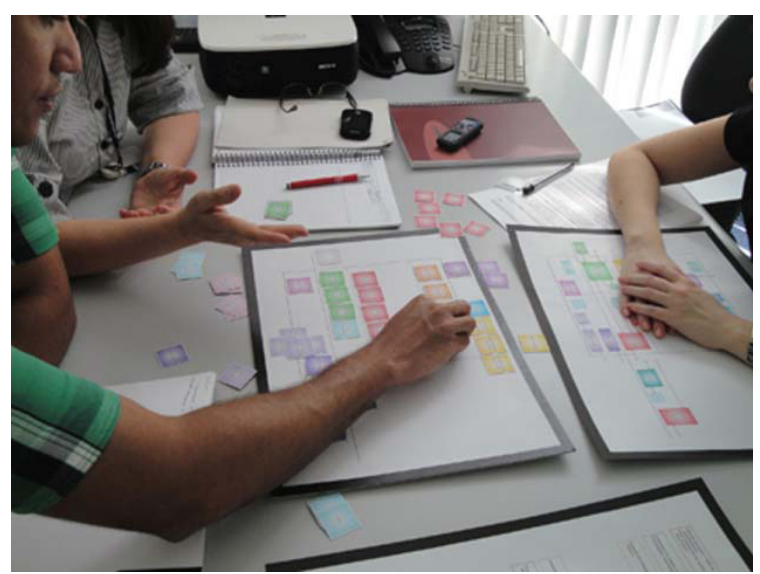

Figure 3 - Design game during the workshop B

To do this there was a magnetized base with the schematic section of the accommodations module and small parts, also magnetized, representing each environment of the module. The pieces followed the same colors as the zoning pattern for easy viewing and comparison between the drawings. During the design game, questionings were being raised to seek explanations for the choices that were being made. Later, from the zoning proposed by the designers, a comparison was made with the zoning pattern developed. After the design game, it was proposed a 'simulation' of use of the zoning proposed by the designers on a recent project for an FPSO.

Since the goal of both tools proposed in this paper was its use in the design phase of the basic project of the accommodations module, the basic design of the FPSO in question was used as a basis for discussion. For this simulation it was developed a basic design of the zoning of that platform: a schematic cut using the same criteria used in the zoning pattern, but representing the basic design developed for this platform. The designers were then asked about the differences identified between the basic design of the FPSO and the zoning proposed by them. Eventually, final questions aimed at the validation of the intermediate objects. The designers were questioned about their opinions on these tools and how they considered that their use could occur in new projects.

\subsection{The results of the workshops}

The results of the workshops can be classified into two main aspects: 1) the zoning pattern itself and the choices made for the positioning of environments, and 2) the possibilities of use of this tool, since the designers made suggestions that differed from the author's initial proposal. Besides these aspects, it also stands out the opinions given by designers on the use of the booklet of recommendations. Regarding the zoning pattern itself, the designers considered that the proposed positioning approached a lot of what they regarded as "ideal", so focus here will be given to the other issues that raised during the workshops.

In workshop $\mathrm{A}$, the proposal revolved around a complement to the tool itself. The designers thought that it would be interesting to have schematic plants to complement the section. The suggestion was to show the relative position of the environments within the positioning of the module on the platform: environments that need to be facing the bow or stern of the ship, eg. Faced with this suggestion and the demand of the positioning all environments that are part of the module, it was observed that the designers sought a tool to approach as close as possible to a standard to be actually followed.

In workshop B, in turn, plans were not considered necessary as a complement to the tool. In this case the designers gave less importance to the possibility of having a very definite pattern as a tool. Instead, they identified the possibility of a design game activity to be performed during the first discussions of the module arrangement with the client company. They pointed out the interactivity with the use of moving parts to assemble the arrangement as a facilitator in these discussions.

Regarding the recommendations booklet, the designers were unanimous in saying they would like to have it as a source of information on projects in which they work. Even the most experienced designers felt that the material has a range of information about the activities they do not always have. Besides being a reference to ergonomic recommendations that are not part of any official design documents.

The results reported here show then an 'approval' by the designers of the proposed tools. Its use as intermediate objects, as well as its final form, would still need final adjustments. However, the proposed concept of transfer of experience for the designers 
use show acceptance from their (possible) future users: the designers.

\section{Discussion}

The notion of intermediary objects was, in the beginning, used to qualify these 'things' that circulated among actors of the process Vinck [19]. These objects represent the ones who developed them (in this case, the ergonomists), being responsible for sharing projections and expectations of actors regarding the future result. However, they do not reduce to their author's intention, once the transition from the intention to the realization does not occur without transformation. That is, something new is always introduced during the process [19], as the interpretation made by the designers, eg.

As it is already said in the literature, the most effective experience transfer contains specific and concise information. And it was with that in mind that the tools presented in this paper were developed. The recommendations booklet attempted to bring the information about the use in a concise way, but giving elements to the designers to interpret and understand them. The zoning pattern, in turn, attempted to bring this information even more concise, by means of a visual representation. The first test and validation of these tools was positive, as seen with the workshops' results. However, a final test would be the use o these tools in a real design process.

But apart of the development of more efficient means of communication, an ergonomist involved in the process is recommended [18,21-23]. The specialist plays an important role as he/she improves the identification of ergonomics issues in the design, may interpret general requirements and is also prepared to enter negotiations when ergonomics are in conflict with other specifications or time/costs constraints. This way, the intermediary objects do not intend to substitute this specialist, who should take part of the design team as the designers of all other disciplines. On the contrary, they intend to help the dialogue among designers and ergonomists, by providing/improving the experience transfer from 'use' to 'design'.

\section{References}

[1] J-F. Boujut and E. Blanco, Intermediary objects as a means to foster co-operation in engineering design, Computer Supported Cooperative Work 12 (2003), 205-219.
[2] O. Broberg, Workspace design: a case study applying participatory design principles of healthy workplaces in an industrial setting, International Journal of Technology Management 51(1) (2010), 39-56.

[3] O. Broberg, Integrating ergonomics into engineering: empirical evidence and implications for the ergonomists", Human Factors and Ergonomics in Manufacturing 17(4) (2007), 353366.

[4] O. Broberg, Integrating ergonomics into the product development process, International Journal of Industrial Ergonomics 19 (1997), 317-327.

[5] J. Campbell, The development of human factors design guidelines, International Journal of Industrial Ergonomics 18 (1996), 363-371.

[6] A. Chapanis, Human factors in systems engineering, John \& Sons Inc., New York, 1996.

[7] F. Daniellou, The French-speaking Ergonomists' Approach to Work Activity: Cross-influences of Field Intervention and Conceptual Models, Theoretical Issues in Ergonomics Science 6(5) (2005), 409-427.

[8] F. Daniellou and P. Béguin, Metodologia da Ação Ergonômica: Abordagens do Trabalho Real, in: Ergonomia, P. Falzon, ed., Editora Blücher, São Paulo, 2007, pp. 281-301.

[9] F. Duarte, F. Lima, R. Remiro and N. Maia, Settings of usage for the design process, in: Proceedings of the 17th World Congress on Ergonomics, Beijing, 2009.

[10]F. Duarte, F. Lima, R. Remiro and N. Maia, Situations d'action caractéristiques et configurations d'usage pour la conception, in : Actes du XXXXIII Congrès de la SELF - Ergonomie \& Conception, Ajaccio, 2008.

[11]B. Ewenstein and J. Whyte, Knowledge practices in design: the role of visual representations as 'epistemic objects', Organization Studies 30(1) (2009), 07-30.

[12]P. Falzon, Ergonomie, conception et développement, in: Actes du XXXX Congrès de la SELF - Ergonomie \& Développement Durable, Saint-Denis de la Réunion, 2005, pp. 30-39.

[13] S. Gherardi and D. Nicolini, To transfer is to transform: The circulation of safety knowledge, Organization 7(2) (2000), 329-348.

[14]F. Guérin, A. Laville, F. Daniellou et al., Compreender o Trabalho para Transformá-lo: a Prática da Ergonomia, Editora Edgard Blücher, São Paulo, 2001.

[15]H. Kim, Effective organization of design guidelines reflecting designer's design strategies, International Journal of Industrial Ergonomics 40 (2010), 669-688.

[16]A. Pagenhart, H. Buset and T. Throndsen, Experience transfer from operational environments to installation design: Why, how and what?, in: Society of Petroleum Engineers International Conference on Health, Safety and Environment in Oil and Gas Exploration and Production, Caracas, 1998, SPE 48828.

[17]R. Seim and O. Broberg, Participatory workspace design: a new approach for ergonomists?, International Journal of Industrial Ergonomics 40 (2010), 25-33.

[18] N. Skepper, L. Straker and C. Pollock, A case study of the use of ergonomics information in a heavy engineering design process", International Journal of Industrial Ergonomics 26 (2000), 425-435.

[19]D. Vinck, De l'objet intermédiaire à l'objet-frontière. Vers La prise em compte $\mathrm{Du}$ travail d'équipement, Revue d'anthropologie des connaissances 3(1) (2009), 51-72.

[20]D. Vinck, A. Jeantet, P. Laureillard, Objects and other intermediaries in the sociotechnical process of product design: an explanatory approach, in: The Role of Design in the Shaping of Technology, J. Perrin and D. Vinck, eds., European Com- 
mission Directorate-General Science, Brussels, 1996, pp. 297. 320.

[21]I. Wulff, B. Rasmussen and R. Westgaard, Documentation in large-scale engineering design: information processing and defensive mechanisms to generate information overload, International Journal of Industrial Ergonomics 25 (2000), 295310.

[22]I. Wulff, R. Westgaard and B. Rasmussen, Ergonomic criteria in large-scale engineering design - I: Management by documentation only? Formal organization vs. designers' perceptions, Applied Ergonomics 30 (1999a), 191-205.

[23]I. Wulff, R. Westgaard and B. Rasmussen, Ergonomic criteria in large-scale engineering design - II: Evaluating and apply- ing requirements in the real world of design, Applied Ergonomics 30 (1999b), 207-221.

[24]S. Zachariassen and S. Knudsen, Systematic approach to occupational health and safety in the engineering phase of offshore development projects - Experience from the Norwegian petroleum activity, in: Society of Petroleum Engineers International Conference on Health, Safety and Environment in Oil and Gas Exploration and Production, Kuala Lumpur, 2002, SPE 73881. 